The RADIAL Model: An Integrated Approach to In-House Communication Training

Judi Brownell

Cornell University

$\underline{\text { Introduction }}$

An organization's ability to promote and maintain effective communication practices becomes ever more critical in the face of rapid change, uncertainty, and high technology (McLagan and Bedrick, 1983). In fact, several years ago a national organization of training and development professionals (the American Society for Training and Development) put increased readiness for change at the heart of its concerns. Employees at all levels need, more than ever before, to process information accurately, deliver messages clearly, write concisely, and work effectively with their colleagues. Communication educators play an increasingly important role, as employees at all levels anticipate dealing with an often chaotic and ever- changing work environment. Clearly, when training professionals examine effective ways of developing a flexible, highly adaptive workforce, communication skills training is high on the list of action steps. Samuel Certo (1985, p.555) explains, "Future-oriented managers must see the future not as an uncontrollable development but as a factor that can be influenced significantly by present ... behavior."

This paper describes the RADIAL model, an innovative approach to in-house communication training that consists of tailored communication training sessions, called "modules," which are facilitated by employees from throughout the organization. This model directly addresses the need for planned, comprehensive, and ongoing training in communication. First, a review of current approaches to communication training provides a context from which 
the RADIAL approach can be examined. The development, implementation, and benefits of the RADIAL model are then discussed.

\section{Communication Training}

Effective training can significantly improve communication competence; communication practices are learned behaviors that can be changed through deliberate intervention strategies (Goldhaber, 1983, p. 425). Models of training (Glaser, 1962; DeCecco, 1968; Wexley and Latham, 1981) have repeatedly emphasized the importance of assessing individual and / or organizational needs, establishing concrete goals, developing instructional strategies, providing feedback, and evaluating the success of the training effort.

In the past few years, increased attention has been given to step one - needs assessment, or what has more recently been labeled the communication audit. Following Howard Greenbaum's (1971) early work, many others (including the International Communication Association, a nonprofit professional organization) have developed structures for appraising both the organization's communication system as well as the effectiveness of member behaviors. Their hope is to identify potential problems before they surface and to generate information about communication practices that will be useful in future planning activities. Early intervention and the prevention of major communication problems has become key to maintaining organizational effectiveness.

Such a move tells us that the most successful training programs are tailored to meet specific organizational requirements. Objectives are generated in response to concrete information from audits conducted within each firm. Trainers are responsible not only for establishing objectives and designing instructional strategies, but also for ensuring that these 
strategies accomplish the desired goals. Training outcomes are measured by the success with which participants handle future organizational communication situations. Does the training have any lasting effect? Long-range evaluation methods are essential to ensure meaningful change and to establish the benefits of training sessions.

Training in general, and communication training in particular, has recently been confronted with new and more demanding challenges. First, employees at all levels — not just management - must develop communication behaviors that will increase their flexibility and improve their performance. Second, training must address the specific needs (both present and future) of organizational members before major problems arise. Finally, training methods must encourage the long-term transfer of learning to the workplace. The RADIAL approach to communication training addresses each of these issues. After examining the characteristics that distinguish this model and reviewing the stages of its implementation, its contributions as a comprehensive and responsive training approach become apparent.

\section{Characteristics of the RADIAL Model}

The RADIAL model is a valuable supplement to more traditional communication training for several reasons. As a preventive, on-going program, it places training at the heart of organizational concerns by using internal, non-training personnel as module facilitators. Their involvement in the program ensures the commitment and responsiveness that are often difficult to achieve with outside consultants. Session packages themselves are flexible and organizationspecific. These characteristics combine to make the RADIAL model substantially different from other approaches to training. 


\section{A Preventive Approach}

Effective training is designed in light of specific organizational requirements and goals; it does not arise only in response to an immediate crisis. The RADIAL training model is designed to upgrade the communication effectiveness of all employees so that major communication breakdowns are less likely to occur. The philosophical basis on which the model was developed holds that increased communication competence and generally heightened awareness of the need for more effective communication itself can "make a difference," positively affecting organizational health and the corporate climate (Pace, 1983). By reaching all employees and bringing communication issues to the surface, individuals are able to solve their own problems and cope more effectively with conflict, change, and daily organizational demands (Redding, 1984; Hershey \& Blanchard, 1977).

\section{$\underline{\text { Use of Non-Training Personnel as Facilitators }}$}

One of the most innovative aspects of this program is that the training sessions, presented in separate modules, are facilitated by non-training personnel from within various parts of the organization. Meaningful change generally occurs to the degree that the training function is viewed as an integral part of the organizational structure; the use of individuals from throughout the organization as key resources (facilitators) makes the training function a central concern. This approach differs from more traditional models which place the sole responsibility for training with the Training and Development or Personnel Departments (Figure 1). When ownership of the program is shared, its credibility is increased. Wexley and Latham (1983, p. 21) note, "training must be diffused throughout the organization so as to become a way of life for 
employees ... change has to spread throughout a significant segment of the organization and be backed by the managers and employees if it is to remain."

Eligible employees become facilitators by participating in training sessions which, through the use of company-specific materials, prepare them both for conducting communication training in general and for implementing specific program modules. Engineers, secretaries, administrative assistants, managers from production, marketing, or finance — all are invited to become candidates for selection to a facilitator pool. The personal and professional development benefit to the individual and the human resource benefit to the company make this a valuable alternative to the more common "trainer as expert" approach. One of the new facilitator's most important tasks is becoming thoroughly familiar with the program of module packages.

\section{$\underline{\text { Module Packages }}$}

Modules are sequenced around a core curriculum consisting of four functional areas: interpersonal skills, presentational speaking, group processes, and written communication (Figure 2). Each area has an introductory, required module which all program participants must take before moving on to other topics in that area. The number of module packages that can be developed in any one of the four categories is virtually unlimited. Categories themselves can, of course, be changed or modified. All content is developed in response to specific organizational concerns.

Each module package, developed in-house with the assistance of a content specialist, contains such materials as:

- objectives for each unit

- recommended format and timeframe 
- text material

- activities, inventories, and other instructional aids

- $\quad$ recommended readings

- $\quad$ assessment instruments

- a pre-program needs analysis and information generating questionnaire

- $\quad$ program evaluation instruments

These materials, although providing structure for the inexperienced facilitators, allow for flexibility and a considerable amount of decision-making on the part of the user. A thorough but concise text provides consistency among various sections of the same module and ensures continuity among sequenced sessions. A wide range of options regarding focus, methods, and activities allows for a creative and session-specific program.

An additional resource, of benefit both to facilitators and participants, is a library for housing print and audiovisual materials related to the various module topics. Facilitators and other organizational members add to this library as they increase their knowledge of available resources. The emphasis is on sharing, learning through experience, practical, property-specific applications, and increasing everyone's awareness of the importance of communication and behavior in achieving persona] and organizational goals. The resource library and other aspects of the program must be put into place carefully.

\section{$\underline{\text { Program Implementation }}$}

The importance of solid endorsement by upper-level management cannot be underestimated as a factor in program success (Hinrichs, 1978; Lathan \& Wexley, 1981). As 
Wexley and Latham (1983) put it, there must be "significant senior management support" for the program, not "passive toleration." Upper-level managers and program administrators must generate enthusiasm, disseminate clear, accurate information, and follow through completely at every stage.

Once a commitment has been made to adopt the module approach, specific content areas are selected for development and implementation. It is helpful to project the introduction of module packages over a minimum of a 5-year period, with 3-5 new packages being introduced each year. An organization may choose to begin with the introductory module in each of the four skill areas, focus on one skill area only, or offer the introductory and a specialized package in each of two or three areas. Long-term success is most likely if developers begin by "going with the winners" - introducing those packages they feel will have the best chance of making a positive and measurable impact on performance. Planning is key to successful implementation of the RADIAL model. Some of the major aspects that must be addressed include: facilitator training, facilitator-participant relationships, pre- and post-session activities, and module evaluation.

\section{Facilitator Training}

All qualified employees are invited to explore the possibility of becoming part of the facilitator team. Each volunteer's immediate supervisor must endorse his or her participation, and may themselves recommend an individual into the program. Individuals who do become facilitators can assume that, in addition to the hours of training required, the) 7 will spend an additional 10-15 hours of initial preparation for each new module they facilitate. 
Criteria for facilitator selection must be established and individual interviews conducted to ensure that all criteria are met. Appropriate criteria are seldom job- specific and might include such items as:

- Experience in the organization

- Personal communication effectiveness

- Interest in professional development activities

- Stage in career development

Once an initial pool of individuals has been selected, all participate in a general train-thetrainer (or train-the- facilitator) program. This session provides another opportunity for administrators to become acquainted with the candidates and to assess each person's potential to become a successful facilitator. Objectives for this session include:

- to prepare each participant to create and maintain a seminar atmosphere conducive to open and constructive communication

- to understand the importance of sharing session objectives with group members so that each session's purpose is clear

- to understand the basic principle of how adults learn

- to enable participants to select appropriate training techniques and to improve each person's competency in such methods as: small groups, presentational speaking, facilitating role plays, case study analysis, providing constructive feedback, using audiovisual materials, and asking and responding to questions

- to instill in each participant a sense of commitment to the program and to foster a sense of community among the facilitators. 
Finally, all facilitators must be made aware of the major ethical issues involved in training. Unethical behaviors identified by members of the American Society for Training and Development (Clement, Pinto, and Walker, 1978) include: violation of employee confidence, failure to give appropriate credit to the work of others, and improper or inappropriate interactions with trainees. The latter includes such behaviors as treating participants as inferior, making racist or sexist remarks, and using profanity. Inexperienced facilitators must be carefully coached and observed to ensure that they perform ethically under all circumstances.

Following the training session, each person receives feedback both from other participants and from the session leader. It is here, too, that individuals have an opportunity to discuss and clarify their roles as facilitators and their relationship to future module participants. This general training session may be repeated every 18 months, generating new facilitator pools as often as necessary.

Individuals who have satisfactorily completed the train-the-trainer program are then ready to be trained in module-specific sessions. Graduates select from among the modules targeted for the coming year those which they prefer to facilitate. Individuals may choose to be trained in all module programs, or wait for training to be offered in one content area. Module-specific training acquaints individuals with the program package, the available options, and the specific content and materials involved. At the end of their first module-specific training session, potential facilitators have had enough contact with the program developers to feel confident in the program's value and comfortable in their roles as session leaders.

Again, the only requirement is that individuals must take the necessary training to facilitate the introductory module of any of the skill areas before progressing to a specific topic in that area. In other words, an individual would complete the training module 'Introduction to 
Interpersonal Communication" first, even if he or she was interested only in facilitating the module on listening or on conflict management. Facilitators, just as module participants, go through training in the introductory module to ensure a common base of fundamental assumptions and definitions before branching out into more specialized topics (Figure 3).

Clearly, facilitators must feel confident and well-prepared in order to create and maintain healthy relationships with module participants.

\section{Facilitator-Participant Relationships}

It appears that, when confronted in the seminar room by their peers (and, at times, their supervisors), facilitators are quickly able to achieve support and cooperation. Credibility does not appear to be an issue if those involved clearly understand and define the facilitator as one who introduces concepts and issues, leads the group in its feedback and processing, and directs the exchange of information. If feelings of goodwill pervade, session participants respect the facilitator and are anxious to work toward common session goals.

In this situation, facilitators are viewed by session participants as resource people who guide, share, coach, and provide a forum for exploration and feedback. The attitudes and nature of the relationship between session facilitators and participants appears to have a positive impact on the learning environment A climate is created in which important issues can surface, often providing themes and questions for later discussion. The sessions supplement the organization's formal communication networks and provide a means of confirming the accuracy of information obtained through informal channels. Quality circles, as well as communication committees and task forces (Wendlinger, 1975), have been used for such purposes in the past, often with considerable success. 
By providing an on-going structure for interaction across traditional organizational boundaries and hierarchies, program modules contribute to employees' sense of involvement and belonging. When employees experience collaborative situations where status differences are minimized, their feelings of personal worth often increase (Korman \& Korman, 1980). These indirect benefits may have as much of an impact on motivating high performance as the content of the sessions themselves.

Since facilitators may come from any unit or department, a variety of alternatives are available in creating an appropriate facilitator/participant group mix. In some instances it is helpful to have employees interact with a facilitator who is familiar with the work environment and immediate situation. In other cases, it may be more desirable to have the facilitator come from another department or division entirely.

Participant groups themselves may be mixed or homogenous. In one instance, clerical staff may need training in memo writing (perhaps led by a member of their own group); in another case, a module on problem solving may be offered to the entire engineering division on a first-come basis. Another question then arises: should training be required, or optional? This depends primarily on its purpose. Certainly, employees who view participation as an opportunity or reward will be more highly motivated and cooperative than those who view the program as remediation. As mentioned earlier, it is essential for the first training efforts to be successful; therefore, it may be wise to begin with elective modules in areas where participants themselves perceive a need to learn. Ideally, even when individuals are "required" to attend various training sessions, this selection will be viewed as a step in their personal and professional development. Participants' initial reactions are likely to be even more positive when they are involved in the planning process itself. This is accomplished through pre-program questionnaires. 


\section{$\underline{\text { Pre-Program Questionnaire }}$}

Pre-program questionnaires are useful in gathering information about the participants' expectations so that module activities and examples may be targeted to meet individual concerns. This instrument, which is part of the module package, serves the additional purpose of insuring that participants are informed about the module's main objectives and have given thought to their personal needs and incentives.

If several sections of the same module are introduced, a number of different facilitators may be conducting the training simultaneously. A pre-program meeting of facilitators is a helpful way to share ideas and provide much-needed peer support. This on-going contact with other facilitators is an important component of the program and can be encouraged further through periodic team-taught modules, meetings of those who regularly conduct the same modules, recognition events, and open invitations to sit in on each other's sessions.

\section{Continuous Follow-up Sessions}

A major concern of communication skills training is how to help participants perform as effectively on the job as they do in the classroom. Behaviors that seem easy by the end of the short seminar are complicated when individuals find themselves alone in the very environment that inspired them to enroll in the first place. The problem? Transfer. How can participants be trained to transfer new skills and attitudes to the workplace?

Much of the success of this process is dependent upon using appropriate methods within the training session itself (Suessmuth, 1978). Clearly, it is important for facilitators to ensure that individuals participate in a variety of activities where they can practice and receive feedback on 
their performances. To expect participants to have internalized behaviors after such a brief instruction period, however, is unrealistic.

In response to this concern, the RADIAL model incorporates, for each module, the concept of continuous feedback and support. The program is highly results-oriented, and several measures are taken to ensure that what was initiated in the seminar does not stop there. Not only do facilitators meet prior to the program for a review of participant needs, they also hold postseminar sessions with graduates of a particular module (there may be multiple sections) on a regular basis, approximately every 5-7 weeks. This series of hour-long follow-up meetings provides participants who elect to attend an opportunity to ask questions and obtain suggestions and support both from their colleagues and from the facilitator. These follow-up sessions continue year around and can be scheduled as informal luncheon meetings. As the number of “graduates" from a particular module increases, more frequent sessions may need to be scheduled.

\section{$\underline{\text { Module Evaluation }}$}

The energy, enthusiasm, and involvement characteristic of communication training often translates very directly into high ratings on program evaluations. After all, it was fun. The group was supportive and optimistic. But are all these good feelings an accurate reflection of the program's impact? Will they last?

Built into every module is a three-point evaluation system that enables facilitators to benefit both from input immediately following the session, and again after some of the initial glow is gone. The first written evaluation, completed immediately following the instructional period, requests information concerning how well the program objectives were met, how 
appropriate the content was to participant needs and expectations, and how well the facilitator accomplished his or her tasks. The questions on this form may also serve as a starting point for a brief wrap-up discussion during the last few minutes of the module session.

Four weeks after the module, participants are asked to complete a written, semistructured progress report. The report asks for information concerning the participant's satisfaction with his or her ability to transfer specific skills to the work environment, and also requests the respondent to reflect on the value of the module material in general. In addition, a third evaluation measure invites participants to give a companion progress report to a supervisor or colleague who is in a position to comment on their pre-module and post module performance. Such input is valuable both to the participants and to the facilitators. This third component is optional and, if employed, participants may choose whether or not to share the information with program administrators. Feedback forms are coded so that participants' self-perceptions can be compared to their colleagues' reports without revealing the identity of either party.

After each new module is implemented, program facilitators meet with the program administrators to review the written feedback forms and make any necessary modifications in the module package. In subsequent sessions, facilitators may review this feedback at the preprogram session when information-generating questionnaires are discussed (Figure 4).

\section{$\underline{\text { Conclusion }}$}

When training and organizational development professionals apply their own futuring skills (Gentilmen, The Bulletin, March 1989, Page 9 \& Nelson, 1983), they realize that, indeed, we face a complex and highly information-centered future. Few measures have as much impact on an individual's ability to adapt to a changing work environment as improved communication 
competence. Strauss and Sayless (1980) agree, pointing out that improving interpersonal relations and involving employees in the solution to organizational problems are two goals effective organizations hare. The RADIAL model, in presenting an alternative approach to these tasks, provides the following additional benefits:

- Program packages are tailored to specific organizational requirements and can be modified periodically

- All communication topics are presented in the same format, providing continuity and easing practical scheduling problems facilitators are provided with maximum opportunity for personal and professional development by serving as program leaders training reaches employees at all levels, strengthening informal networks and building employee commitment

- Facilitators are provided with maximum opportunity for personal and professional development by serving as program leaders training reaches employees at all levels, strengthening informal networks and building employee commitment

- A three-point evaluation system ensures transfer from the training session to the workplace

- On-going follow-up sessions provide interested participants with continuing support and feedback

- The program is cost effective.

The RADIAL model ensures that as employees place one hand on a computer terminal, they nevertheless keep the other hand open, reaching out to their colleagues for ideas and support. What better way to develop human resources than to introduce and nurture the employee 
relationships that strengthen the organizational fabric by building trust and fostering a collaborative, supportive climate. In chaotic, rapidly changing environments, the RADIAL model focuses the organization's attention on its human links and creates a framework within which all employees can improve their performance by developing a wide range of essential communication behaviors. 


\section{$\underline{\text { References }}$}

Certo, S. C. (1986). Principles of modern management: Functions and systems (3rd ed). Dubuque, I A: Wm. C. Brown, Publishers.

Clement, R. W., Pinto, P. R., \& Walker, J. W. (1978). How do I hurt thee? Let me count the ways: Unethical and improper behavior by training and development professions.

DeCecco, J. (1968). The psychology of learning and instruction: Educational psychology. Englewood Cliffs: Prentice-Hall.

Gentilman, R. \& Nelson, B. (1983). Futuring: The process and implications for training and development practitioners. Training and Development Journal, (June), 31-38.

Goldhaber, G. M. (1983). Organizational communication (3rd ed). Dubuque, IA: Wm. C. Brown, Publishers.

Glasser, R. (1962). Psychology and instructional technology. In R. Glasser (ed.), Training Research and Education. Pittsburgh: University of Pittsburgh Press.

Greenbaum, H. (1971). Organizational communication systems: Identification and appraisal. Paper presented at a meeting of the International Communication Association, Phoenix.

Hershey, P. \& Blanchard, K. (1977). Management of organizational behavior: Utilizing human resources (3rd ed). Englewood Cliffs: Prentice-Hall.

Hinrichs, J. R. (1978). Practical management for productivity. New York: Van Nostrand Reinhold.

Korman, A. K. \& Korman, R.W. (1980). Career success /personal failure. Englewood Cliffs: Prentice-Hall.

Latham, G. P. \& Wexley, K N. (1981). Increasing productivity through performance appraisal. Reading: Addison- Wesley. 
McLagan, P. A. \& Bedrick, D. (1983). Models for excellence: The results of the ASTD training and development competency study. Training and Development Journal (June), 12.

Pace, R. W. (1983). Organizational communication: Foundations for human resources development. Englewood Cliffs: Prentice-Hall.

Redding, W. C. (1984). The corporate managers guide to better communication. Glenview, IL: The Scott, Fores- man PROCOM Series.

Strauss, G. \& Sayles, L. R. (1980). Personnel: The human problems of management (4th ed). Englewood Cliffs: Prentice-Hall, Inc.

Wendlinger, R. M. (1975). Using a task force to improve employee communication: Bank of America’s approach. Academy of Management Review, 64(8), 25-30.

Wexley, K. N. \& Latham, G. P. (1981). Developing and training human resources in organizations. Glenview, IL: Scott, Foresman and Company. 
TRADITIONAL MODEL
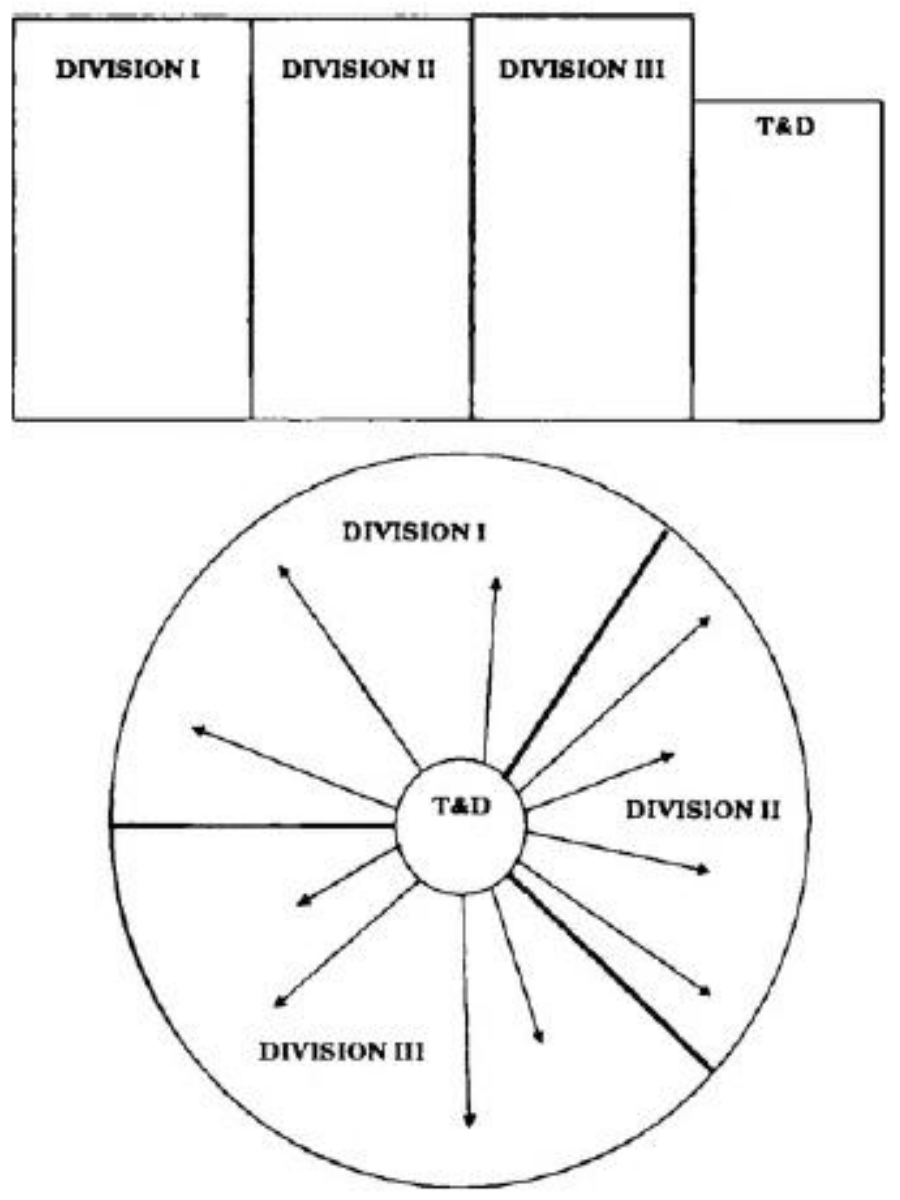

RADLAL MODEL

Trained facilitators $\boldsymbol{\nabla}$ come from all parta of the organization. Figure 1 
CURRICULUM OF COMMUNICATION SKILL AREAS

$\begin{array}{ll}\text { INTERPERSONALSKILIS AREA } & \text { PRESENTATIONAL SKIILS AREA } \\ \text { Introduction to Interpersonal Skills } & \text { Introduction to Presentational Speaking } \\ \text { (Prerequisite to other modules in area) } & \text { (Prerequisite to other modules in area) } \\ \text { Listening Skills } & \text { Persuasive Speaking } \\ \text { Nonverbal Skills } & \text { Use of Visual Aids } \\ \text { Conflict Management } & \text { Speech Delivery } \\ \text { Interview Skills } & \text { Speaking for Special Occasions } \\ \text { Assertive Skills } & \text { Advanced Presentational Speaking } \\ \text { ETC. } & \text { ETC. } \\ \text { GROUP SKILLS AREA } & \text { BUSINESS WRITING SKILLS AREA } \\ \text { Introduction to Group Process } & \text { Introduction to Business Writing } \\ \text { (Prerequisite to other modules in area) } & \text { (Prerequisite to other modules in area) } \\ \text { Leadership Skills } & \text { Writing Letters } \\ \text { Problem Solving Discussion } & \text { Writing Memos } \\ \text { Decision Making in Groups } & \text { Writing Proposals } \\ \text { Creativity in Groups } & \text { Writing Technical Reports } \\ \text { Building Teammanship and Morale } & \text { Writing for Public Relations } \\ \text { ETC. } & \text { ETC. }\end{array}$

Any number of additional topic areas can be added to each of the four categories.

Figure 2 
FACILITATOR TRAINING

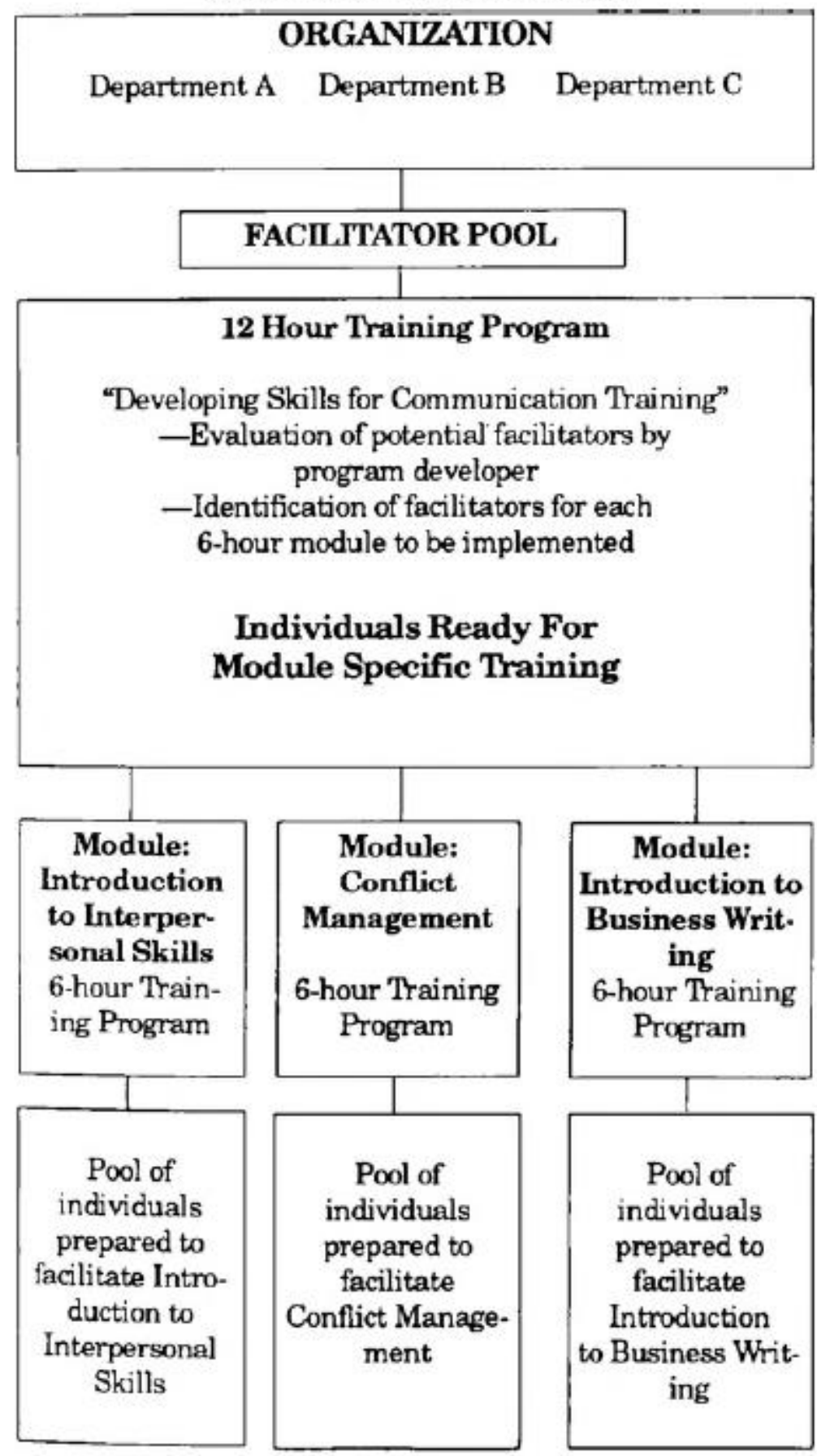

Specific Facilitators Selected

To MatchParticipant Group

Figure 3 
MODULE IMPLEMENTATION

\begin{tabular}{|c|}
\hline IDENTIFY PARTICIPANT GROUP \\
\hline IDENTIFY INDIVIDUAL FACILITATOR(S) \\
FOR GROUP \\
\hline $\begin{array}{c}\text { DISTRIBUTE PRE-PROGRAM QUESTIONNAIRE } \\
\text { TO PARTICIPANT GROUP }\end{array}$ \\
\begin{tabular}{|c|}
\hline $\begin{array}{c}\text { FACILITATOR(S) REVIEW PRE-PROGRAM QUESTION- } \\
\text { NAIRE }\end{array}$ \\
(And feedback from previous progtams, if applicable) \\
-Facilitators consult with program developer \\
-Facilitators review materials in communications \\
resource room
\end{tabular} \\
\hline
\end{tabular}

FACILITATORS CONDUCT 6-HOUR MODULE

-Immediate module evaluation by participants

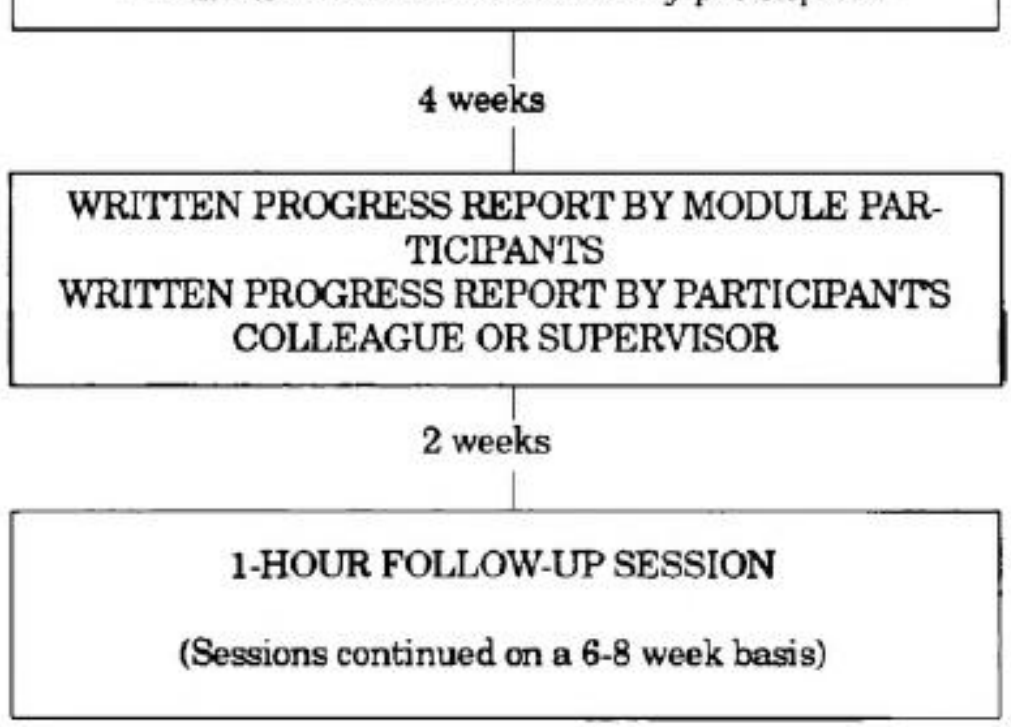

FIRST TIME MODULES: Meeting of program developer, training staff, facilitators

Figure 4 